7. Reprod. Fert. (1966) 12, 205-212

\title{
PRO-OESTRUS IN THE GUINEA-PIG: HORMONAL STIMULATION OF THE VAGINAL EPITHELIUM
}

\author{
RUTH DEANESLY \\ A.R.C. Institute of Animal Physiology, Babraham, Cambridge \\ (Received 21st Fanuary 1966)
}

\begin{abstract}
Summary. Earlier experiments on guinea-pigs are said to demonstrate the essential participation of small amounts of progesterone at normal oestrus.

The guinea-pig vagina shows an elaborate proliferation just before oestrus, with stratified epithelial cells at the base, which eventually cornify, and loosely arranged mucified cells next to the lumen. Attempts with different hormones to reproduce this transitory condition in spayed females have shown that it is slow to develop but can be induced by 6 to $12 \mu \mathrm{g}$ oestradiol benzoate spread over 3 to 4 days. This is enough for full vaginal oestrus including cornification and, in some females, mating. There was no evidence from these experiments of pre-ovulatory progesterone being a significant factor at oestrus.
\end{abstract}

\section{INTRODUGTION}

At pro-oestrus the guinea-pig vagina shows a striking epithelial proliferation (PI. 1, Fig. 2a); the lower layers are stratified and have cornified, and above them, projecting into the lumen, are mucified cells whose nuclei are degenerating. Plate 1, Fig. 2(b), from the same vagina, shows a later stage of mucified cell degeneration shortly before the whole mass is swept into the lumen at oestrus. This mucified epithelium is comparable to the foliaceous proliferation found in the golden hamster vagina (Deanesly, 1938), which is also shed at oestrus. The mouse has a much slighter mucification (Mirskaia \& Wiesner, 1930) at pro-oestrus, than has the rat; Korenchevsky \& Hall (1937) described it as 'pseudo-mucified' and were unable to reproduce it with exogenous hormones in the spayed female.

Pregnancy-type mucification in the vagina, on the other hand, can readily be reproduced after ovariectomy in the rat (Klein, 1935; Jones \& Astwood, 1942), mouse (Robson, 1938), hamster (Klein, 1937) and guinea-pig (Deanesly, 1960 , with earlier references) by combinations of oestrogen and progesterone.

If the characteristic pro-oestrous proliferation of a guinea-pig could similarly be reproduced in the spayed female it should throw light on the hormonal conditions at oestrus, and in particular it might provide evidence of the preovulatory progestagen postulated in the guinea-pig by Dempsey, Herz \& Young (1936), Herz, Meyer \& Spielman (1937), Boling, Young \& Dempsey 
(1938) and others from the results of mating experiments, and further discussed by Ford \& Young (1951) in relation to cyclic vaginal smears.

Young $(1941,1961)$ has reviewed the evidence that progesterone or some progestagen is essential for full oestrus in a number of species, but histological confirmation of its presence is still lacking. In the guinea-pig the vaginal proliferation is fully developed at first oestrus, when no corpora lutea are present, and the early stages coincide with the growth of the follicles. According to Rowlands \& Short (1959), progesterone is restricted to the corpora lutea in the guinea-pig ovary.

Early pro-oestrous guinea-pigs often show 'mounting' activity, which might indicate the presence of ovarian androgens, although Young, Dempsey \& Hagquist (1937) found that such activity is correlated with the number of ripening follicles and probably oestrogen-stimulated.

In the present experiments, oestradiol, androstenedione, testosterone propionate and progesterone, alone or in combination, have been given in various dosages to spayed guinea-pigs and the results, from which certain conclusions can be drawn, are described.

\section{MATERIALS AND METHODS}

The guinea-pigs were from the colony at the National Institute for Medical Research, London, where the work was begun or from the colony at the A.R.C. Institute of Animal Physiology, Babraham, which had similar animals. Steroid hormones were injected subcutaneously in oil, once daily, unless otherwise stated; oestradiol was given as oestradiol benzoate. Injected guinea-pigs were examined either once or twice daily.

In previous work on mated guinea-pigs, the morning when the vaginal plug was found, was recorded as Day 0 ; the vagina at this stage is usually closing and the follicles have ruptured. On the same system in normal, unmated females the following days are (luteal) Days 1, 2, etc.

All guinea-pigs were ovariectomized under ether anaesthesia. In the eighteen females in Series A this was done on Days 7 to 11 in the second half of the luteal phase and injections were begun on the same or on the following day. In the thirty-five guinea-pigs of Series B injections were begun at various times up to 6 months after ovariectomy, and Day 1 is the first day of treatment. Vaginal opening commonly occurred on Day 4 or 5 . Most animals were killed then or on the following day if the opening was partial, in the hopes that the vagina would show a full pro-oestrous proliferation; others were killed 1 day after the last injection.

Histological material was fixed in Bouin's fluid and sections from two or more parts of each vagina were stained in haematoxylin with or without eosin; many sections were also stained with alcian blue or periodic acid-Schiff and Orange $\mathrm{G}$ for mucin.

\section{THE NORMAL GYGLIC AND PRO-OESTROUS VAGINA}

Sections through the vaginae of twelve non-pregnant, mated and unmated guinea-pigs were examined from luteal Day 6 until after the next oestrus. In the mid-luteal phase of the cycle the epithelium is only two to four cells thick with a 
single layer of more or less cuboid mucified cells next to the lumen (Pl. 2, Fig. 5); it is indistinguishable from that of the spayed female (Pl. 2, Fig. 4). From about Day 12 there is an increase in the mucified epithelium till it is about eight cells deep, the cells also enlarging (Pl. 1, Fig. 1, and Pl. 2, Figs. 6 and 7); mucified cells occupy most of the epithelium but the basal layer has thickened slightly and is more distinct ( $\mathrm{Pl}$. 2, Fig. 7). This is the early pro-oestrous stage, before stratified and cornified epithelium has differentiated.

As oestrus approaches there is a change and the basal layers give rise to stratified epithelial cells with vesicular nuclei (Pl. 2, Fig. 9) which develop rapidly. The mucified epithelium loosens and spreads further into the lumen, but its nuclei degenerate (Pl. 1, Fig. 2a and b). The process continues during the stratification and eventual cornification of the basal layers which appear to push away the degenerating mucified cells. The final stages of this striking process take place rapidly at about the time the vagina opens. Growth and cornification of the basal layers seem to coincide with the last day of the cycle when the mucous cell proliferation has passed its peak. Dempsey (1937), in a study of the enlargement of the follicles of the guinea-pig, records a steep increase in their size during the last day of the cycle, which may well coincide with a rise in oestrogen secretion.

As would be expected, there is variation in the timing of the vaginal epithelial development as in the actual length of the cycle, and this must be allowed for in considering the experimental results of Series A. The epithelium, moreover, can differ in different parts of the long vagina; oestrous changes appear first at the cervical end.

\section{EXPERIMENTAL RESULTS}

Qestradiol: effects of 1 to $4 \mu \mathrm{g}$

As already observed (Bacsich \& Wyburn, 1942; Rowlands, 1962; Jagiello, 1965), relatively low doses of oestrogen will induce vaginal opening in the spayed guinea-pig; 1 to $2 \mu \mathrm{g}$ oestradiol in oil, injected over 2,3 or 4 days is enough, and the amounts suggested by Ford \& Young (1951) for inducing fully cornified smears in spayed females seem very high.

Out of seven guinea-pigs of Series A, ovariectomized and injected in the same cycle with a total of 1 to $2 \mu \mathrm{g}$ oestradiol, six showed vaginal opening and some vaginal epithelial proliferation, but nothing like the full normal pro-oestrous or oestrous condition. After four injections of $0.25 \mu \mathrm{g}$ oestradiol beginning on luteal Day 9, one female killed on Day 13 with the vagina still closed, showed the early pro-oestrous condition (Pl. 2, Fig. 8)-a build-up of mucified epithelium with no proliferation of the lower layers. In three other females the lower layers had become cornified, but with no significant proliferation of mucified epithelium.

Animals, including eight in Series $\mathrm{B}$, which received up to $4 \mu \mathrm{g}$ oestradiol, had transitional epithelium with some increase of both cell types. The vagina, however, in all cases lacked the full pro-oestrous proliferation, in spite of variations in the splitting and timing of the doses and in the day of autopsy. In Series A guinea-pigs the actual epithelial growth was probably affected by the nearness of the coming oestrus at ovariectomy. 
As in the spayed mouse (Marrian \& Parkes, 1930), amounts of exogenous hormone which will induce vaginal opening are not necessarily sufficient for inducing full oestrus and mating behaviour.

\section{Oestradiol and progesterone}

Earlier work on spayed guinea-pigs (Deanesly, 1960), showed that mucification of the vaginal epithelium, such as occurs in normal pregnancy from about Day 18, can be induced in the spayed female by daily injections of 5,2 or $1 \mathrm{mg}$ progesterone together with $1 \mu \mathrm{g}$ oestradiol. As in the rat (Jones \& Astwood, 1942), this type of completely mucified epithelium tends to be better developed if an appropriate dose of progesterone is combined with an increased proportion of oestrogen, e.g. $5 \mu \mathrm{g}$ oestradiol with $1 \mathrm{mg}$ progesterone daily.

In the present experiments on nine females, varied but small amounts of progesterone $(0 \cdot 1$ to $1 \mathrm{mg}$ daily for 1 to 6 days), comparable to those of Dempsey et al. (1936), were given with oestradiol totalling 1.2 to $6 \mu \mathrm{g}$. The vagina opened but the results were negative for the pro-oestrous proliferation; five females killed on Days 5 to 7 had mucified epithelium of the pregnancy type (Pl. 3, Fig. 13) and the others had transitional epithelium, less developed than with similar doses of oestradiol alone. The mucification of pregnancy, or a similar mucification produced by exogenous hormones, is the result of an inhibition of the lower epithelial layers by progesterone and it is unlikely that the latter would be present at pro-oestrus in biologically active amounts when the basal epithelium is multiplying rapidly.

\section{Oestradiol and androstenedione}

Androstenedione occurs in the follicular fluid of mare ovaries and by analogy with other species it may well be secreted in small amounts by the guinea-pig ovary (Short, personal communication). epiAndrostenediol has a mucifying action on the vaginal epithelium of the ovariectomized guinea-pig in a dose of $2 \mathrm{mg}$ daily for 10 days (Deanesly \& Parkes, 1937) and it seemed possible that an ovarian androgen might contribute to the pro-oestrous proliferation.

Various combinations of oestradiol $(0.05$ to $0.5 \mu \mathrm{g}$ daily) and androstenedione ( 5 to $10 \mathrm{mg}$ daily) were given to six guinea-pigs of Series A and five of Series B. The vagina opened in all except one but the vaginal epithelium was variable and never fully developed, though proliferation of both mucified and stratified layers could be seen. Detailed comparisons of sections with those from females subsequently receiving similar doses of oestradiol only indicated that the androstenedione had not caused any distinctive changes, although it perhaps contributed to the epithelial proliferation when in combination with low doses of oestradiol ( $0.25 \mu \mathrm{g}$ daily for 4 days), as in No. 238 (Pl. 3, Fig. 14) and certain others. Androstenedione by itself ( $40 \mathrm{mg}$ in 4 days), did not cause vaginal opening and had no obvious effect on the epithelium.

\section{Oestradiol and testosterone propionate}

Two Series B guinea-pigs each received $5 \mathrm{mg}$ testosterone propionate with 
$5 \mu$ g oestradiol on Days 1, 4 and 8 and were killed on Day 10. In both females the vaginal epithelium was deeply mucified as in pregnancy with only a flattened basal layer. Apparently testosterone had an inhibiting action like that of progesterone on pro-oestrous changes including the growth of stratified epithelium.

\section{Oestradiol: further experiments}

After the failure to obtain a pro-oestrous proliferation from the combinations of hormones, it was decided to use larger doses of oestradiol. Most of these were given over 3 or 4 days and the dosage gradually increased to simulate the normal cyclic rise in oestrogens; total doses ranged from 4.75 to $12 \mu \mathrm{g}$. Of the twelve guinea-pigs, all but one from Series B, seven were killed on Day 4 when the vagina opened, four on Day 5 and one on Day 6 . Between them the experimental animals showed all the normal stages of vaginal proliferation, though the stage of maximum proliferation (Pl. 1, Fig. 3) was rare, and desquamating cornified epithelium with degenerating mucified cells in the lumen more common. In few of the animals had the mucified epithelium reached its full foliaceous development before degenerating. The best developed was in No. 577 which was given 2, 2 and $4 \mu$ g oestradiol on successive days and killed with open vagina on the 4th Day, and in No. 625 (P1. 1, Fig. 3) killed on the 6th Day after gradually increased amounts of oestradiol totalling $6 \mu \mathrm{g}$. In both these guinea-pigs the vagina was fully cornified below the mucified epithelium, but there was more degeneration of the latter in No. 625 (PI. 1, Fig. 3). In seven other animals of this group the vaginal epithelium was well-developed and cornified, but most or all of the mucified cells had been shed into the lumen. In the remaining three females given 6, 6 and $12 \mu$ g respectively and killed on Days 4 and 5, the epithelium was transitional and not fully developed (Pl. 3, Figs. 10, 11 and 12), though both mucified and stratified layers were growing actively.

In four spayed females which received much larger amounts of oestradiol $(20,20$ and $40 \mu \mathrm{g}$ or 60,60 and $80 \mu \mathrm{g}$ on 3 successive days) the vaginal reaction was somewhat different on Days 4 or 5 when they were killed, all but one with the vagina open. There was no stratification of cornification of the epithelium, but a marked increase in the number and especially the size of the mucified cells (Pl. 3, Fig. 15).

The absence of stratification and cornification is difficult to explain; it can only be supposed that the oestrogens caused such active mucification as to inhibit any other development of the epitheliurn.

To sum up-it is clear that in suitable amounts oestradiol can by itself induce a full proliferation of the vaginal epithelium in the spayed guinea-pig. Although the vaginal epithelium is a very sensitive indicator of circulating hormones, the experiments provide no evidence that pre-ovulatory progesterone is normally present or necessary at oestrus, although it may be formed in quantities too small to produce a histological reaction.

For obvious reasons the guinea-pigs in this study of the pro-oestrus vaginal reaction were not mated, but six other ovariectomized ones, given 6 to $12 \mu \mathrm{g}$ oestradiol, were put with males and three vaginal plugs were found. 


\section{DISCUSSION}

Many attempts to reproduce the elaborate pro-oestrous proliferation of the vaginal epithelium in spayed guinea-pigs with various doses of steroid hormones were unsuccessful, although the vagina opened in almost all the treated animals. Eventually, however, all stages of vaginal epithelial growth were stimulated with oestradiol benzoate alone. In a long series of papers (see Young, 1941, 1961), Young, Dempsey and their associates have maintained that full oestrus in the guinea-pig and some other species required a small amount of progesterone, derived from the pre-ovulatory follicle, which 'touches off the oestrous mechanism'. The present results makes this conclusion improbable since the vaginal epithelium, a highly sensitive indicator of circulating hormones, shows only evidence of oestrogen stimulation, and spayed females receiving 6 or $10 \mu \mathrm{g}$ oestradiol have mated normally. Histologically undetectable amounts of progesterone may indeed be present but they cannot be essential for full oestrus, in the guinea-pig.

Progesterone in the ovariectomized guinea-pig has no effect on the vagina (Deanesly, 1960) but in association with oestrogens, as in normal pregnancy, it causes complete mucification to the base of the vaginal epithelium. Such mucification can be stimulated in the spayed guinea-pig by the two hormones together and the progesterone has the effect of inhibiting a proliferation of the basal layers such as occurs in response to oestrogens.

The histological results suggest that the build-up of vaginal epithelium takes about 4 days and begins very slowly, affecting first the mucified cells next to the lumen (Pl. 1, Fig. 1). This build-up can hardly be stimulated by progesterone since it begins near the end of the luteal phase (Pl. 2, Fig. 6) and also before the first ovulation (Pl. 2, Fig. 7). Very few of the experimental animals had this type of epithelium in which the mucified cells have increased but not the basal layers. Presumably this was due to doses and timing - the mucified epithelium not having a long enough developmental period before differentiation of the stratified epithelium. This would account for the numerous animals which at autopsy had a transitional epithelium with some development of both mucified and stratified cells but nothing like the full pro-oestrous proliferation (Pl. 3, Figs. 10, 11 and 12).

Even with increased oestradiol doses (6 to $12 \mu \mathrm{g}$ ) it was not easy to determine if a normal vaginal proliferation had always been induced owing to the rapidity of the changes during the last period of epithelial growth and desquamation. In females killed too long after treatment, the mucified epithelium consists only of degenerate fragments with fully cornified epithelium below.

\section{ACKNOWLEDGMENTS}

The author gratefully acknowledges a personal grant from the Medical Research Council.

Plates 1 to 3, Figs. 3 to 15 are the work of Mr Gallup, A.R.C. Institute of Animal Physiology, Babraham. 


\section{REFERENCES}

BAcsich, P. \& WYBURN, G. M. (1942) Observations on artificially induced heat in immature guineapigs. Proc. R. Soc. Edinb. B, 61, 188.

Boling, J. L., Young, W. G. \& Dempsey, E. W. (1938) Miscellaneous experiments on the estrogenprogesterone induction of heat in the spayed guinea-pig. Endocrinology, 23, 182.

DeanesLy, R. (1938) The reproductive cycle of the golden hamster (Cricetus auratus). Proc. zool. Soc. Lond. 108,31 .

DeanesLy, R. (1960) Endocrine activity of the early placenta of the guinea-pig. F. Endocr. 21, 235.

Deanesly, R. \& Parkes, A. S. (1937) Multiple activities of androgenic compounds. $Q . \not{f l}$ exp. Physiol. 26, 393.

DEMPSEY, E. W. (1937) Follicular growth rate and ovulation after various experimental procedures in the guinea-pig. Am. F. Physiol. 120, 126.

Dempsey, E. W., Hertz, R. \& Young, W. C. (1936) The experimental induction of oestrus (sexual receptivity) in the normal and ovariectomized guinea-pig. Am. F. Physiol. 116, 201.

Ford, D. H. \& Younc, W. G. (1951) The role of progesterone in the production of cyclic vaginal changes in the female guinea-pig. Endocrinology, $49,795$.

Hertz, R., Meyer, R. K. \& Sprelman, M. A. (1937) The specificity of progesterone in inducing sexual receptivity in the ovariectomized guinea-pig. Endocrinology, 21, 533.

JAGIELLO, G. (1965) Effects of selected hormones on the closed vaginal membrane of the ovariectomized guinea-pig. Proc. Soc. exp. Biol. Med. 118, 412.

Jones, G. E. S. \& Astwood, E. B. (1942) The physiological significance of the estrogen: progesterone ratio on vaginal cornification in the rat. Endocrinology, 30, 295.

KLEIN, M. (1935) Recherches sur la mucification de l'épithelium vaginal au cours de la grossesse chez la ratte. C. r. Séanc. Biol. 119, 577.

Klein, M. (1937) The mucification of the vaginal epithelium in rodents. Proc. R. Soc. B, 124, 23.

Korenchevsky, V. \& HALL, K. (1937) The bisexual and co-operative properties of the sex hormones as shown by the histological investigation of the sex organs of female rats treated with these hormones. J. Path. Bact. 45, 681 .

Marrian, G. F. \& Parkes, A. S. (1930) The relative amounts of oestrin required to produce the various phenomena of oestrus. J. Physiol., Lond. 69, 372.

Mrrskaia, L. \& Wiesner, B. P. (1930) On endocrine basis of mating in mouse. Q. Fl exp. Physiol. $20,273$.

Ronson, J. M. (1938) Mechanism of oestrus inhibition in the mouse during pregnancy. $Q . J l$ exp. Physiol. 28, 195.

RowLANDS, I. W. (1962) The effect of oestrogens, prolactin and hypophysectomy on the corpora lutea and vagina of hysterectomized guinea-pigs. 7. Endocr. 24, 105.

RowLANDs, I. W. \& SHORT, R. V. (1959) The progesterone content of the guinea-pig corpus luteum during the reproductive cycle and after hysterectomy. F. Endocr. 19, 81.

Young, W. C. (1941) Observations and experiments on mating behaviour in female animals. Q. Rev. Biol. 16, 135, 311.

Young, W. C. (1961) The hormones and mating behaviour. Sex and Internal Secretions. 3rd edn, Chap. 19. Baillière, Tindall and Cox, London.

Young, W. G., Dempsey, E. W. \& HagQuist, C. W. (1937) Factors influencing the character of heat in the guinea-pig. (Abstract). Anat. Rec. 70, 48. 


\section{EXPLANATION OF PLATES}

Guinea-pig vaginal epithelium

PLATE $1(\times 225)$

FIG. 1. No. 173. Early normal pro-oestrous stage with well-developed mucified epithelium above a thin basal layer.

Fig. 2(a). No. 159. Fully developed vaginal proliferation at pro-oestrus, the vagina just open.

FIG. 2(b). No. 159. Mucified epithelium breaking down in another part of the same section as Fig. 1.

Frg. 3. No. 625. Series B. Vaginal epithelium from spayed female which had $6 \mu$ g oestradiol over 5 days and was killed when the vagina opened on Day 6 ; pro-oestrous proliferation well developed.

PLATE $2(\times 275)$

FrG. 4. No. 252. Vaginal epithelium from guinea-pig 15 days after spaying.

FIG. 5. No. 69. Vaginal epithelium from normal guinea-pig on luteal Day 6; epithelium low as in Fig. 4.

Fig. 6. No. 203. Vaginal epithelium from normal guinea-pig on luteal Day 14; there is an increase in the mucified epithelium but not in the basal layer.

Fig. 7. No. 181. Well-developed mucified epithelium in a normal guinea-pig just before the first oestrus; this is a slightly later stage than that of Pl. 1, Fig. 1. There is a mitosis in the basal layer, but it shows little increase.

Fig. 8. No. 329. Series A. Ovariectomized on luteal Day 9 and given $0.25 \mu$ gestradiol on Days 9, 10,11 and 12; killed Day 13, vagina closed. Mucified epithelium developing as in Fig. 7.

Fig. 9. No. 245. Series A. Ovariectomized on luteal Day 10 and given $0.5 \mu$ gestradiol on Days 10,11 and 12; killed on Day 13 with the vagina open. Epithelium transitional with some differentiation of both mucified and stratified layers, but not resembling that of a normal pro-oestrus.

\section{PLATE $3(\times 275)$}

FIG. 10. No. 572. Series B. Transitional epithelium in a guinea-pig given 2, 2 and $5 \mu \mathrm{g}$ oestradiol and killed with the vagina open on the 4th day.

FIG. 11. No. 492. Series B. Transitional epithelium in which the stratified layers are more differentiated. This guinea-pig which had three daily injections of $2 \mu \mathrm{g}$ oestradiol 6 months after ovariectomy, was killed with the vagina open on the following day.

FIg. 12. No. 532. Series B. Transitional epithelium in a guinea-pig which had 2, 2, 4 and $4 \mu \mathrm{g}$ oestradiol on successive days and was killed on the following day with the vagina open. A well-developed but not a normal pro-oestrous proliferation.

Frg. 13. No. 342. Series A. Ovariectomized on luteal Day 7 and given $0.5 \mathrm{mg}$ progesterone on Days 7 and 8 and $1 \mu$ g oestradiol on luteal Days 9,10 and 11 when the vagina opened; killed the next day. Epithelium mucified throughout, as in pregnancy, with flattened basal cells.

Fig. 14. No. 238. Series B. Rather similar to Fig. 13, but this guinea-pig received 0.25 $\mu \mathrm{g}$ oestradiol and $10 \mathrm{mg}$ androstenedione daily for 4 days and was killed with the vagina open on the following day.

FIG. 15. No. 518. Series B. This female had 60,60 and $80 \mu \mathrm{g}$ oestradiol on successive days and the vagina opened on the next day when the animal was killed. The epithelium consisted of very large mucified cells resting on an undifferentiated basal layer. 


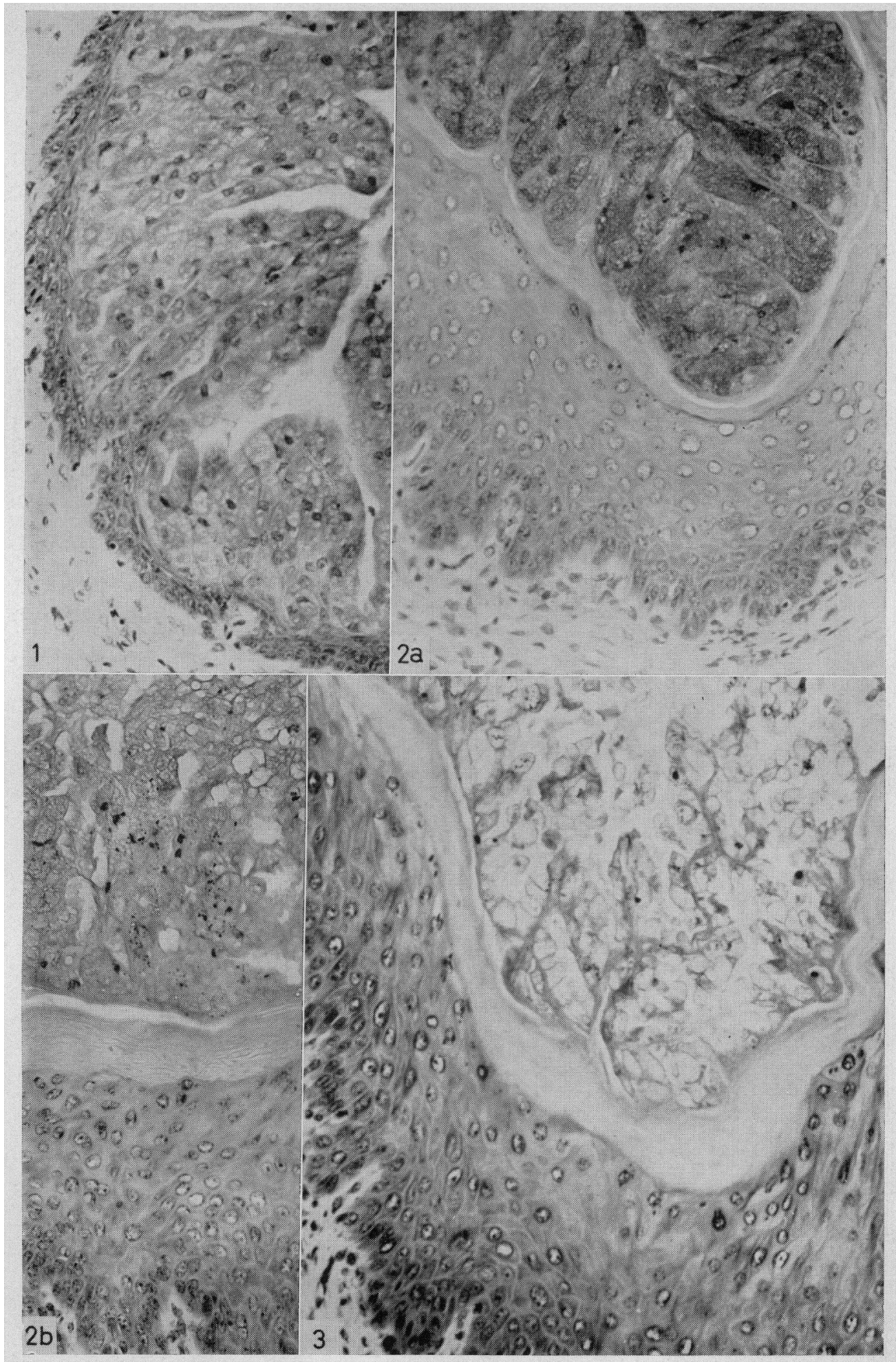


PLATE 2

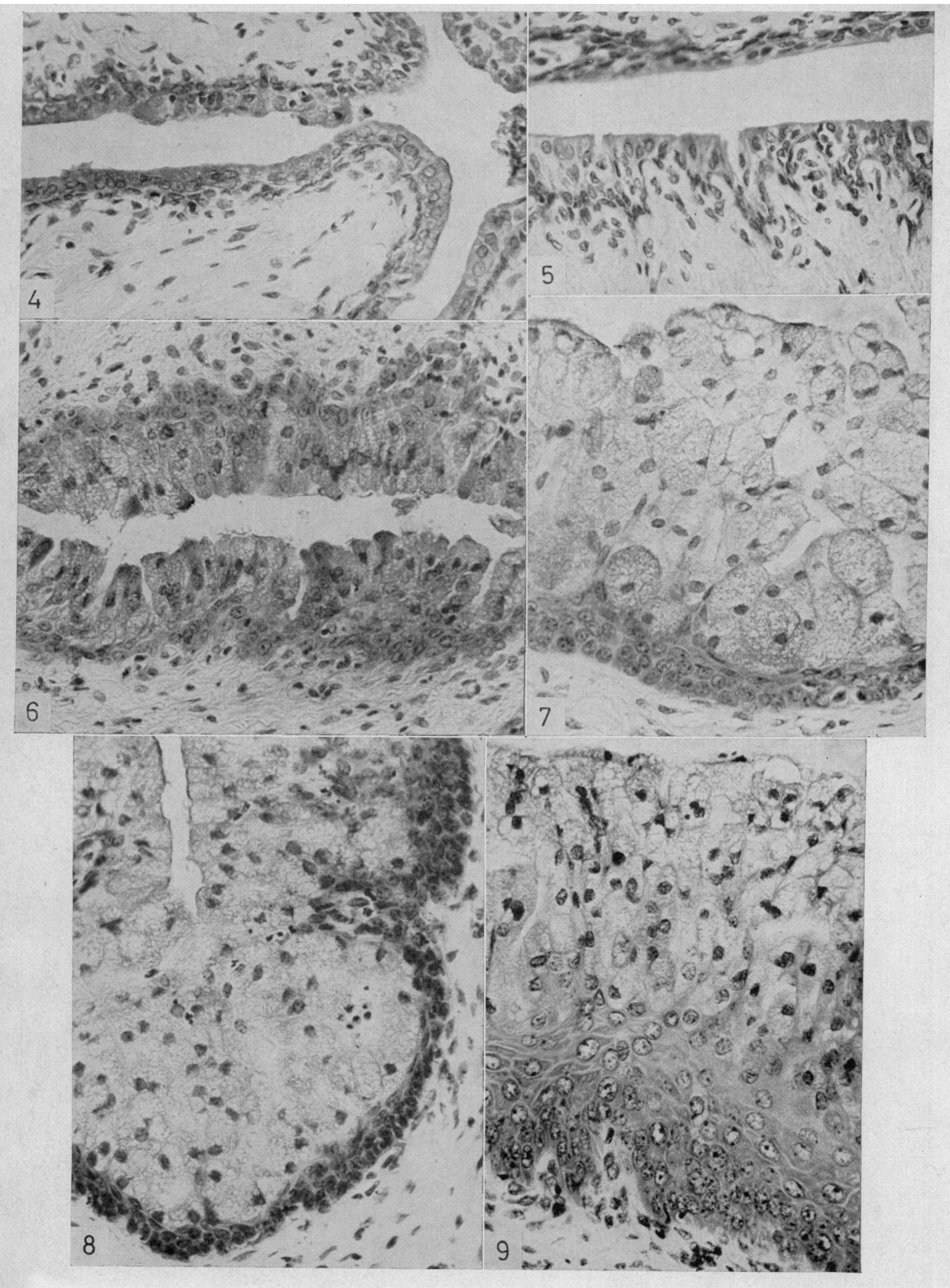




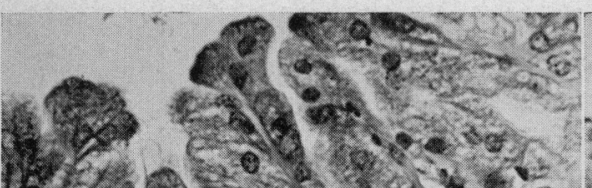

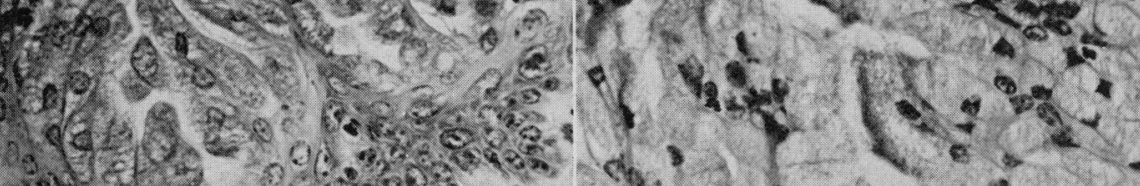
a)

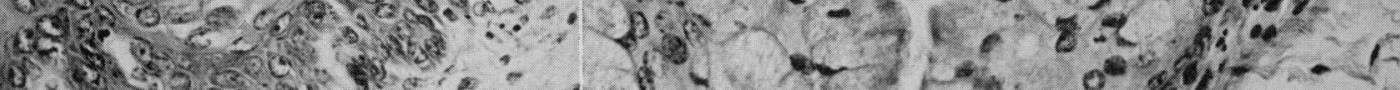

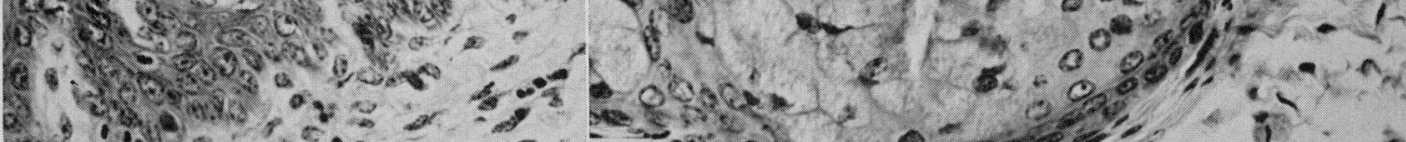

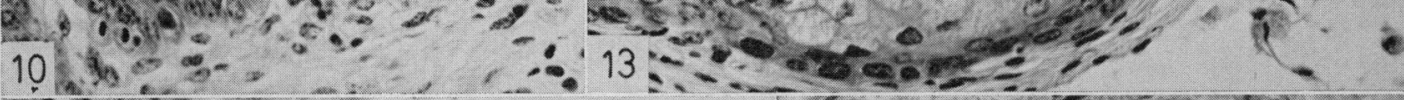

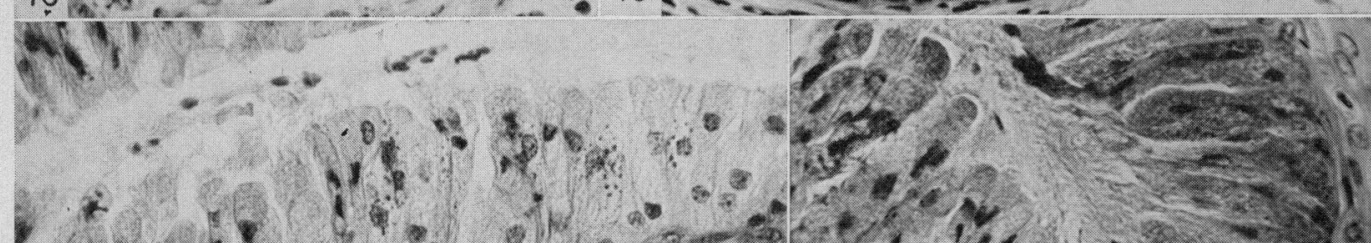

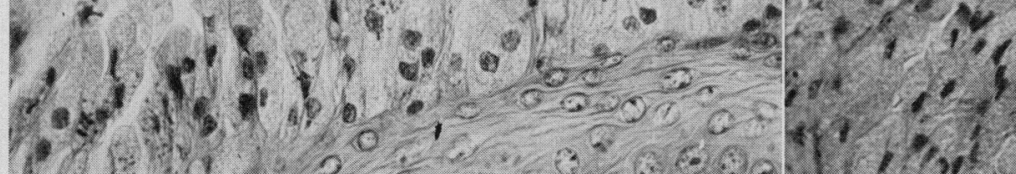

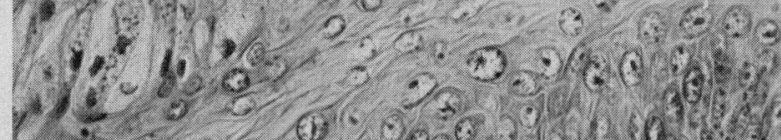

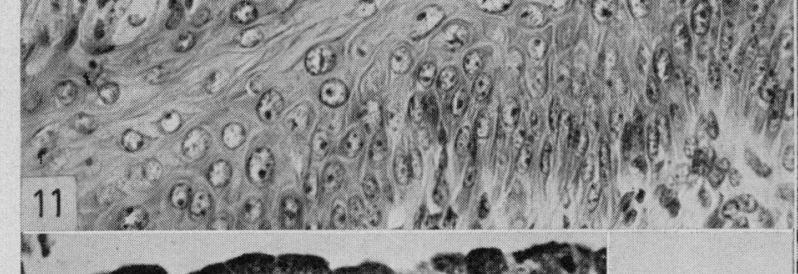

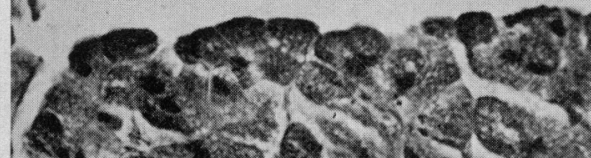

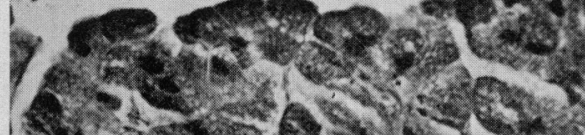

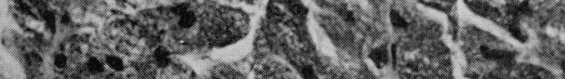

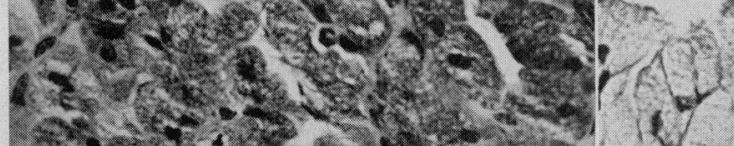

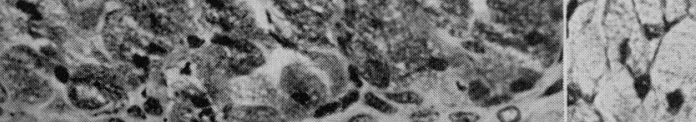

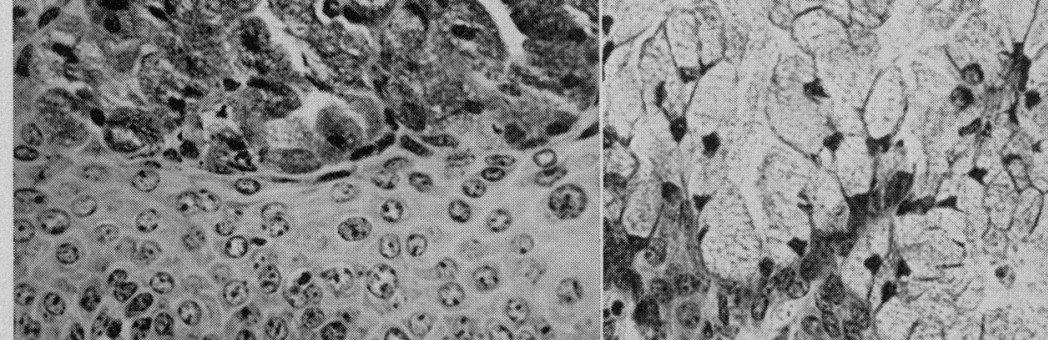

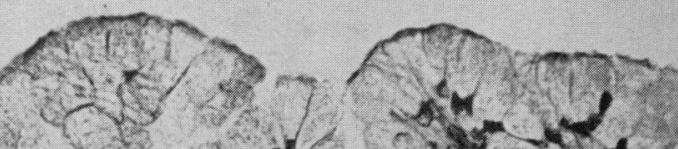
6.

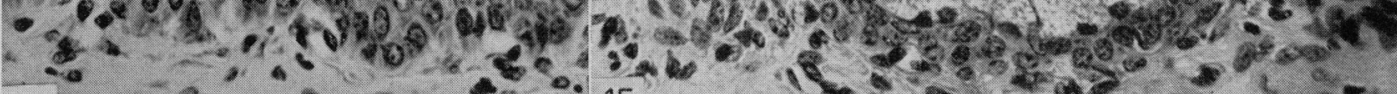

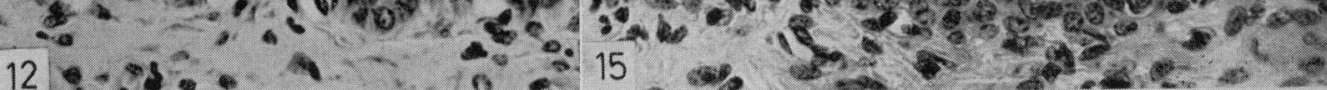

